\title{
TEMAS, TENDÊNCIAS E DESAFIOS DA GEOGRAFIA NA PÓS-GRADUAÇÃO BRASILEIRA
}

\author{
Francisco Mendonça ${ }^{1}$ \\ Professor da Universidade Federal do Paraná \\ chico@ufpr.br
}

\section{Resumo}

A formação em nivel de pós-graduação brasileira tem uma historia muito curta e muito recente. Ela apresenta aspectos contraditorios que revelam ao mesmo tempo boa qualidade de formação, alta concentração espacial e consideravel rigidez no sistema de avaliação. A geografia, neste contexto, repercute problemas e vantagens que refletem o geral deste nivel de formação, além de aspectos proprios de sua identidade disciplinar. Uma reflexão acerca das categorias e dos processos de analise geográfica evocados pelos cursos e programas stritu sensu em desenvolvimento no Brasil possibilitaram traçar um perfil da abordagem geográfica na pós-graduação no país. 'As categorias ambiente, espaço e territorio, as mais evocadas, associam-se processos tais como gestão, desenvolvimento, organização, ordenamento e planejamento, o que revela uma clara resposta da academia às preocupações atuais da sociedade. Como principaís desafios ao aperfeiçoamento da geografia na pós-graduação aparecem, dentre outros, a busca por caminhos alternativos para atender à demanda do hinterland brasileiro, particularmente da Amazônia, e a criação de cursos voltados à analise geográfica na escala da nação.

Palavras-chave: Geografia, pós-graduação, categorias, processos, Brasil.

\section{Abstract}

The brazilian graduate formation has a short and very recent history. It presents paradoxal aspects that disclose at the same time good quality of formation, high space concentration and considerable rigidity in the evaluation system. Geography, in this context, reverberates problems and advantages that reflect the generality of this leval of formation, beyond the aspects of its identity disciplining. A reflection concerning the categories and of the processes of geographical analyzes evoked by the stritu sensu courses and programs in development in Brazil make possible to trace a profile of the geografical boarding in the pos-graduation in the country. To the categories environment, space and territory, the most evoked, associate processes such as management, development, organization and planning, what it discloses a clear reply of the academy to the current concerns of the society. As main challenges to the perfectioning of geography in the pos-graduation they appear, amongst others, the search for alternative ways to take care of to the demand of hinterland Brazilian, particularly of the Amazônia, and the creation of courses come back to geografical analyzes in the scale of the nation.

Key Words: Geography, graduate formation, categories, process, Brazil.

L'âge des Lumières a fortement contribué à rejeter dans l'irrationnel toute raison qui ne serait pas forcée à la science. Or je tines qu'il y autant de raison chez Montaigne ou Verlaine que dans la physique ou la biochimie et, réciproquement, parfois autant de déraison éparse dans les sciences que dans certains songes. La raison est statisquement distribuée partout: nul ne peut en revendiquer 1'exclusive possession. (SERRE, 1992 (pg. 79).

Muito tardiamente, ou somente no alvorecer da Modernidade, a formação escolar no nivel superior, ou universitário, se institucionalizou no Brasil. Comparativamente à boa parte dos países ocidentais, e mesmo a uma considerável parte de países latinoamericanos, o ensino universitário brasileiro consolidou-se em tempos muito mais recentes, sendo que constitui uma marca do século XX. A pós-graduação, então, é uma conquista que se consolida apenas no final do século, sobretudo quando se considera a dissonância entre cronologia e determinados eventos historicos paradigmáticos (HOBSBAWM, 1995).

O ensino escolar publico é basilar no processo de desenvolvimento de uma nação, pelo menos no contexto da modernidade. O atraso de sua institucionalização, no Brasil, é um dos principaís fatores a 
responder pelas alarmantes condições de injustiça e exclusão social, portanto de subdesenvolvimento, manifestadas de diferentes formas no territorio nacional.

Falar da pós-graduação soa quase que desconfortante quando observados os indices de analfabetismo, de semi-analfabetismo e de formação escolar primaria incompleta da população brasileira. Todavia, um processo de ensino-aprendizagem responsável não pode se restringir a somente uma ponta da formação, ainda que uma tal visão pareça coadunar-se mais com as reflexões emanadas daquela de mais alto nivel escalar, elite que é no âmbito da sociedade. Dispensável, pois que envolto em certo cabotinismo corporativo, evidenciar aqui os argumentos favoráveis e as decorrências positivas de um bom desempenho das atividades de formação pos-universitária para uma dada sociedade.

E' neste contexto de formação tardia, porém de boa qualidade e com consolidação rápida, que a geografia acadêmica brasileira se insere. Um tal processo revela, por suas proprias caracteristicas, um conjunto de questionamentos nem sempre fáceis a responder de maneira satisfatoria, afinal a geografia tem suas especificidades e seus conflitos. Algumas constatações e uma analise critica do processo, além de alguns desafios à pós-graduação (strito senso) em geografia no Brasil são abordados no âmbito deste texto. Para sua elaboração optou-se por idenfiticar e analisar as categorias de estudo e as dimensões da analise geográfica evocadas pelos cursos e programas de pós-graduação em geografia no Brasil.

\section{Evolução e disparidades regionais da formação e da pesquisa em geografia no Brasil}

A Revista n. 1 da ANPEGE, lançada em 2003, contempla, na maioria de seus textos, uma reflexão relativa à construção da pós-graduação em geografia no Brasil. Visões não muito diferenciadas, no seu geral, evidenciam aspectos particulares dos contextos historicos de criação, evolução e consolidação dos cursos e programas de pós-graduação da geografia brasileira. Os autores, em sua maioria, são unânimes ao destacar a concentração geográfica de mestrados e doutorados em geografia no Brasil, o que pode ser observado na figura 1, que contempla também os cursos e programas recomendados pela CAPES Coordenação de Aperfeiçoamento de Pessoal de Nivel Superior - em 2003 e 2004.

Nos dois ultimos anos, mesmo com a criação de mais alguns cursos de mestrado (UFC e UFPA) e de programas de doutorado (UFPE e UFRGS) recomendados pela CAPES, a desconcentração esboça ainda fraca tendência. Somente a muito recente criação do mestrado da UFPA é que destoa, levemente, da distribuição observada até então e, ao contrario do que considera o Documento de Area (www.capes. gov.br, 2005), a carência não se apresenta somente para a região Norte. Uma ampla area que cobre todo o interior das regiões Nordeste, Centro-Oeste, oeste da região Sul e, claro, quase toda a região Norte, não dispõe de cursos de geografia neste nivel de formação.

Esta situação não é, todavia, uma caracteristica apenas geográfica e da geografia; ela o é da ciência acadêmica brasileira no geral, e particularmente do seu mais elevado patamar - a pós-graduação, como o mostram Therry et Mello (2004) ao mapearem os dados relativos à pós-graduação brasileira. Mesmo com esta "proliferação concentradora", aspecto que reflete também a concentração demográfica, economica e politica do país como o demonstram os recentes dados do IDH-M brasileiro (IPEA, 2004), muito há ainda a se fazer pela popularização e democratização do ensino e do conhecimento acadêmico no Brasil. Em todo caso, um total de apenas 29 cursos e programas é muito pouco quando se observa uma população de mais de 170 milhões de habitantes e a dimensão do territorio nacional. Estes dados, quando comparados a outros países, constituem prova cabal do atraso social do país.

Todavia, a reprodução de modelos de formação escolar americano-europeus na realidade brasileira tende a refletir a situação acima apresentada. As exigências de critérios cada vez mais rigidos, embasados 
em padrões internacionais de países desenvolvidos, limitam a criação de novos cursos e inibem, portanto, a possibilidade de expansão da pós-graduação no país. Ainda, a embaraçosa demanda da pré-existência de "massa critica" com suporte teorico para a implantação de um mestrado ainda continuará legando a muitos, principalmente àqueles que residem e trabalham no hinterland brasileiro, a oportunidade de continuidade de suas formações. Os atuais cursos e programas reconhecidos com nota igual ou superior a 4,0 não conseguem, por seu lado, atender à demanda da criação de cursos interinstitucionais, sobrecarregados que são pelas constantes demandas de melhoria na performance e na produção intelecutual dos proprios cursos sede.

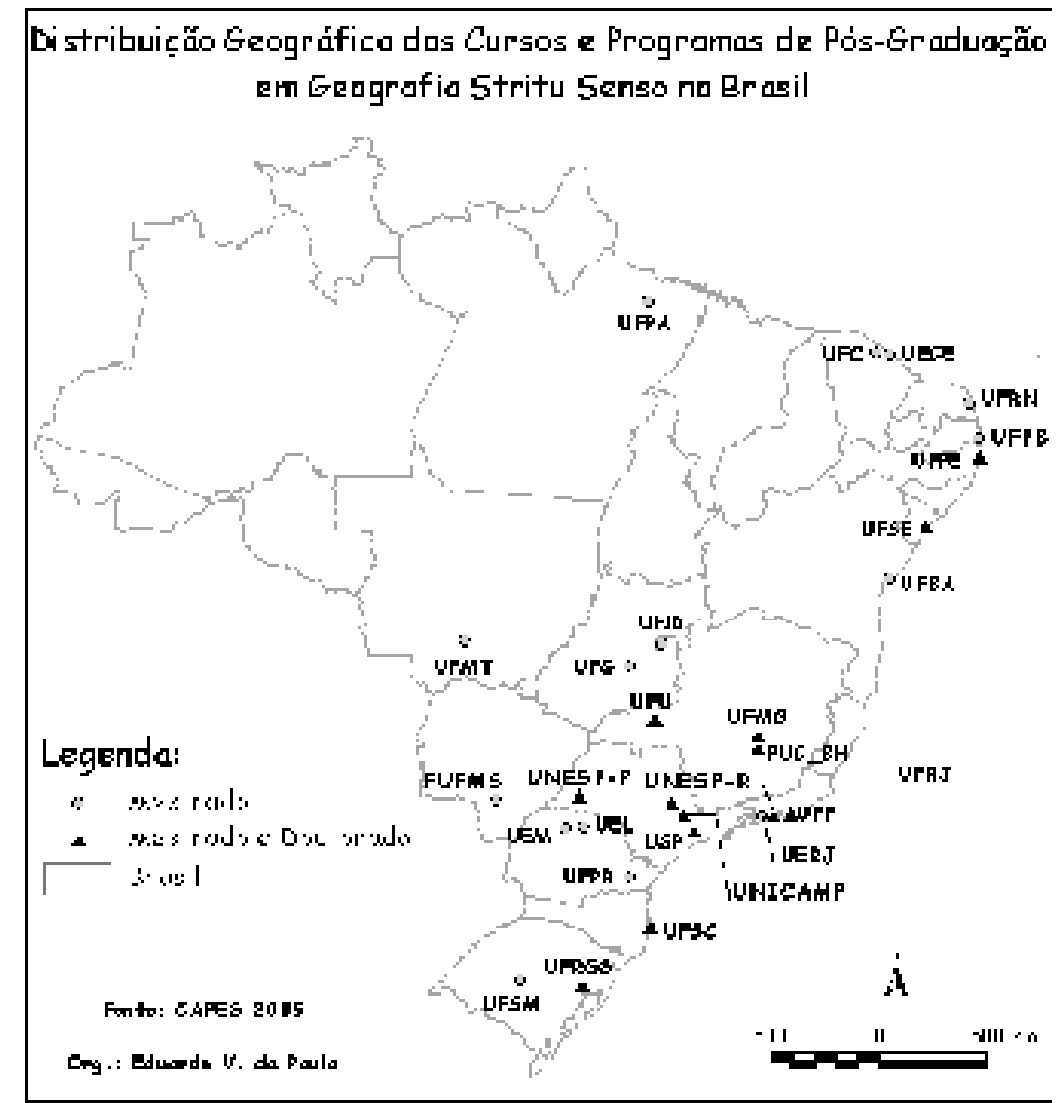

Figura 1: Distribuição Geográfica dos Cursos de Pós-Graduação em Geografia Stritu Senso no Brasil

Tem sido muito mais facil ao sistema promover o deslocamento de um considerável numero de pessoas do "Brasil profundo" (ou hinterland) em direção aos "grandes centros", que criar e implementar programas piloto de formação e pesquisa nas chamadas "áreas (geográficas) carentes". Criticos afoitos concebem este tipo de ação como sendo um novo tipo de "colonialismo interno", nominação fácil que perpetua a geopolitica concentradora e deslocacional. Este processo mais antigo de um tipo particular de colonialismo, parece importante assinalar, não passa somente na reprodução muitas vezes acritica do "conhecimento" conduzido nas malas em interminaveis viagens e na mente exausta, ele tem que ser permanentemente repetido até às mais distantes fronteiras administrativas e imateriais do territorio 
nacional, vangloriado e reificado. Geográfico de primeira grandeza ele torna-se, surpreendentemente, muito mais importante que o proprio lugar.

A experiência da vida local e a riqueza de conhecimentos dela adquiridos parecem ainda insuficientes para engrenar cursos que, associando o aporte teorico-epistemologico e metodologico produzidos em centros mais avançados, pudessem embasar novas propostas no vazio do hinterland do país como acima constatado. Não se trata de abrir mão da qualidade do ensino e formação superior, primeira acusação à uma tal reflexão, mas parece necessario buscar novas formulações para a produção do conhecimento, afinal o principal "laboratorio da posmodernidade" não deveria se limitar à copia de modelos ou à reprodução de estruturas que a modernidade dos dias atuais ja demonstrou claramente a ineficácia e insuficiência para a gestão dos problemas sociais. Trata-se de usar da criatividade e buscar propostas alternativas, embasadas em outros parametros de qualidade (que tal a geograficidade?), pois que num modelo de credenciamento e avaliação por demasiado concentrador ${ }^{3}$, com suas vantagens e desvantagens, o risco do "pensamento unico" esta sempre em evidência.

E' desta maneira que, por mais de vinte anos, cursos de áreas completamente diferentes são avaliados sob critérios iguais, fato que legou às ciências "moles" - à geografia dentre outras - conceitos em geral baixos e aportes financeiros irrisorios quando comparadas às ciências "duras", cujas coorporações se impuseram desde há muito no poder de decisão dos orgãos gestores da politica de pós-graduação. E' a logica de produção e reprodução destas que se impõe sobre aquelas, algo estranho, pois a clássica e historica diferenciação entre estruturas de pensamento e de conhecimento entre os campos do saber parece não ter sido levada em conta na organização burocratica das instituições de fomento ao ensino e à pesquisa no Brasil.

Adaptados e condicionados a um modelo que tende cada vez mais a reproduzir a produção material em série ("quanto mais diplomas melhor"), e no menor tempo possivel, o sistema vai revelando homogeneizações assustadoras. Dissertações e teses com extensos capitulos de discussão teorica-metodologica reproduzem, de norte a sul do país, quase sempre os mesmos autores, notadamente aqueles que publicam nas grandes editoras comerciais. Os estudos de casos vão sendo, em geral, secundarizados diante de tão elevada importancia acordada aos aspectos teorico-metodologicos dos estudos monograficos, e é a geografia e o conhecimento detalhado acerca do lugar, da paísagem, da região e do territorio que perdem, que se empobrecem. Chegou-se a uma situação tal que um trabalho acadêmico em geografia acaba sendo mais valorizado pelas referências que faz (principalmente internacionais) do que pelo conhecimento geografico que produz acerda dos lugares. Assim, parece necessário o levantamento de bandeiras que, de fato, clamem pelo estudo aplicado das categorias de analise do pensamento geográfico e que defendam, enfim, uma geografia que valorize mais o geográfico.

Mas não é somente a formação na pós-graduação que responde por estas caracteristicas criticáveis. A pesquisa também apresenta suas particularidades. A concentração geográfica dos pesquisadores com bolsa de produtividade do $\mathrm{CNPq}$, por exemplo, constitui apenas um aspecto desta realidade. No caso da geografia isto é ainda mais evidente, pois as regiões Sudeste e Sul são as grandes concentradoras, sendo que somente os estados do Rio de Janeiro e São Paulo, dentro destas, destacam-se pela quase totalidade dos bolsistas.

Se esta concentraçao responde pelo fato de a maior parte dos pesquisadores estarem vinculados a instituições destas regioes geográficas, ela é insuficiente para sustentar uma situação de concentração de poder e de beneficios. Graves conflitos são resultantes desta situação que representa um Brasil do passado, afinal, pelo menos o quadro de pesquisadores e docentes qualificados das regiões Sul, Nordeste 
e Centro-Oeste alterou-se sensivelmente na ultima década. E mesmo na região Norte mudanças aconteceram e evidenciam uma melhoria na titulação dos pesquisadores desta area do país. Este contexto revela, todavia, um descompasso entre a concentração da representação e a disseminação da qualificação, vide os programas de pós-graduação stritu sensu.

\section{Categorias e processos de analise predominantes: Reflexos da, ou diretrizes para a geografia brasileira?}

Malgrado os problemas que marcam a formação em nivel de pós-graduação e a pesquisa em geografia no Brasil, consideráveis avanços têm sido observados na sua evolução recente. A maioria dos textos da Revista n. 1 da ANPEGE (2003) torna possivel uma caracterização deste nivel de formação em geografica; além destes deve-se também ressaltar que Monteiro (2001) tentou esquematizar - a exemplo de sua avaliação anterior (Monteiro, 1980) e em outra tentativa para o Seminario Geografia $2001^{4}$ - as tendências atuais da geografia feita no Brasil. Contudo, dada à complexidade atual das tendências e sobretudo à falta de avaliação baseada em levantamento sistemático à base de indicadores confiáveis, as duas esquematizações apresentadas são para serem vistas como meras impressões ${ }^{5}$.

Uma breve avaliação dos temas principaís dos cursos e programas, assim como das áreas de concentração e linhas de pesquisa construidas por cada formação em funcionamento, permitem traçar um perfil da produção intelectual da geografia brasileira na pós-graduação, como se vera a seguir.

Não se pode afirmar, todavia, que as opções feitas para a presente analise reflitam o atual quadro de preocupações e de interesses dos geografos brasileiros, ou se evidenciam apenas o interesse de determinados grupos que objetivam conduzir e aprofundar a produção do conhecimento geográfico acerca de temáticas precisas. Num primeiro momento acredita-se que os temas deveriam estar representados na produção intelectual dos grupos envolvidos com os cursos e programas, pois que derivariam da experiência e da produção dos mesmos, o que garantiria a coerência e a consistência das propostas. Mas, a realidade, pela sua propria dinâmica e riqueza, contém elementos que escapam à esta condição otima almejada pela CAPES, o que significa dizer que nem toda a produção de um determinado curso esteja limitada ao que a área de concentração anuncia.

Para traçar um breve perfil da geografia brasileira, a abordagem aqui desenvolvida reteve-se na analise das categorias e temas identificados junto aos cursos e programas de pós-graduação em geografia no Brail.

\section{Categorias de analise geografica na pós-graduação.}

Os dados relativos às categorias e aos processos da analise geográfica apresentados nos quadros 1 e 2 foram levantados a partir das áreas de concentraçao e às linhas de pesquisa dos cursos e programas de pós-graduação em geografia no Brasil (www.capes.gov.br, 2005). Para a analise dos dados excluir-se-a do gráfico n. 1 as "categorias" geografia fisica e geografia humana, pois estas estão mais afeitas às duas macrodivisões classicas do conhecimento geográfico moderno, sendo que não constituem categorias de analise da geografia como o aqui concebido.

Por categorias de analise entende-se, no âmbito deste texto, os recortes ou as especificades geográficas da superficie da Terra utilizadas para o exercicio intelectual e a produção do conhecimento no âmbito da ciência geográfica. São estas categorias de analise, algumas concebidas como "conceitos operacionais" por Suertegaray $(2003)^{6}$, que explicitam a dimensão temporo-espacial da descrição e analise de um determinado fato geográfico. Estas categorias o caracterizam como tal, ou seja, evidenciam a atribuição geográfica de um dado conhecimento produzido numa determinada época e lugar; um conhecimento 
portanto detentor de uma dimensão historica e espacial.

A geografia é, por sua propria natureza e caracteristica, um saber dual (Mendonça, 1999) e complexo (Silva e Galeno, 2005), donde uma consideravel profusão de possibilidades de abordagens de seu objeto de estudo. Esta caracteristica pode ser também observada numa boa quantidade de formações em nivel de pós-graduação, instancia na qual o aprofundamento do conhecimento no âmbito cientifico adquire a possibilidade de uma maior especialização. Neste patamar, o conhecimento cientifico parece atingir o panteão da modernidade, pois que revela ao mesmo tempo a supremacia entre a ciência e a técnicatecnologia, entre o aprofundamento e a especialização, e entre o individualismo e a disciplinaridade. E a geografia recente-se disto, pois que seu maior aprofundamento parece ser concomitante a um maior estabelecimento de relações e intercâmbios com outros campos do saber.

Das categorias elencadas como "concentradoras" (Quadro 1) de interesse para a geografia na pósgraduação, a abordagem relativa ao "rural" e à "natureza" aparecem de maneira bastante tênues, constando como preocupações centrais de apenas dois cursos no país. "A natureza" aparece, na sua grande maioria, empregada sob o enfoque do "meio ambiente", como se verá a seguir, e está geralmente envolvida com os enfoques da geografia fisica. O "rural", predominante na geografia brasileira de até a segunda metade do século XX, parece ceder lugar às abordagens do "urbano", o que evidencia, de certa maneira, uma preocupação com o processo de urbanização acelerado, descontrolado e caotico, que se observa no país com maior destaque nas ultimas decadas. $\mathrm{O}$ urbano aparece, de maneira direta, como uma categoria à qual os cursos atribuem um pouco mais de atenção que às duas precedentes, pois que é mencionado em áreas de concentração de dois cursos no país. Todavia, o detalhamento permitido pelas linhas de pesquisas dos cursos e programas possibilita observar que rural e urbano aparecem como importantes categorias de analise da geografia brasileira na atualidade, em varios cursos pelo país.

"Região" e "Territorio", diferentemente das categorias anteriores, são evocadas, cada uma, em sete dos 29 cursos e programas no país. Conceitos classicos e de cunho eminentemente geográficos, da geografia moderna, a região e o territorio aparecem de maneira muito direta nas linhas de pesquisa de varios cursos, além das menções nas áreas de concentração, aspecto que reflete o reforço e a especificidade da identidade geográfica das formações objetivadas.

"Espaço" e "Ambiente" são categorias que aparecem de forma mais enfática no discurso geográfico em tempos mais recentes. De maneira geral as categorias região, territorio e espaço aparecem como englobando as clássicas abordagens dos aspectos relacionados às atividades humanas na superficie da Terra. Região e territorio mantém perspectivas tanto clássicas quanto inovadoras da formação em geografia no Brasil, mas sob a categoria "espaço" aparecem sobretudo novas abordagens, ai incluidas a "geografia cultural" e a "geografia social". Nesta ultima perspectiva identifica-se um certo alinhamento da estrutura da formação pretendida com a corrente da Geografia Critica e também ao pensamento do geografo Milton Santos.

Sob o rotulo da categoria "Ambiente" agrupa-se uma considerável quantidade de propostas (14) que outrora poderiam estar agrupadas sob o "guarda-chuva" da geografia fisica no seu geral, ou atreladas a alguns de seus ramos especificos. As inovações trazidas com a emergência e importancia da questão ambiental na atualidade parecem constituir um mote para um retorno do olhar geográfico a uma de suas mais importantes vertentes: a abordagem integrada da paísagem e dos problemas derivados da apropriação da natureza pela sociedade. Esta "onda" ambiental na geografia brasileira assemelha-se àquela observada em varios países do Ocidente nas tres ultimas décadas, pois que a relação sociedade - natureza foi mais uma vez colocada em questão face aos graves problemas que colocam em risco a vida sobre o planeta. $\mathrm{Na}$ sua especificade a questão ambiental demanda uma analise multiescalar, tanto espacial quanto temporal, 
e neste aspecto o conhecimento geografico tem muito a contribuir.

Mas, ainda que interessantes no seu todo, parece necessario estabelecer diferenças entre a geografia fisica e a abordagem ambiental (MENDONÇA, 2003) na formulação de propostas de formação de pósgraduação, sobretudo neste nivel da formação acadêmica. A geografia fisica, por exemplo e a despeito da quase ausência de um debate mais aprofundado de sua episteme contemporânea, se viu reduzida de maneira impactante com o exagerado emprego do termo ambiental, que não a substitui nem em suas generalidades e menos ainda em suas especificidades. A vanguarda garantida pela temática ambiental aparece, assim, como ameaça a uma das principaís subdivisões da geografia. Esta situação é ainda mais expressiva no nivel de pós-graduação quando comparada à graduação, e nem toda produção geográfica deve ser alcunhada de ambiental, é preciso insistir!

A questão ambiental é, todavia, atrelada a vantagens e desvantagens ao conhecimento geografico, mas demanda aos geografos um melhor discernimento quanto à seu embasamento teorico, bem como ao aspecto dos estudos aplicados. Ela é, ao mesmo tempo e sem sombra de duvidas, uma perspectiva unificadora das dicotomias e dualidades do pensamento geografico (Mendonça, 1993; Mathews and David, 2004), permitindo-lhe o tratamento mais integral da paísagem e portanto uma rica contribuição à solução de graves problemas da atualidade. Ela constitui, ainda, uma clara possibilidade de resposta dos geografos a uma demanda atual da sociedade, além de qualifica-los para atuarem na vanguarda de muitos movimentos sociais em busca da qualidade de vida e da melhoria das condições de vida da população. Mas exige dos geografos, ao mesmo tempo atenção e cuidado, pois é preciso evitar as generalizações e obviedades que todo e qualquer tema midiático incorre.

As categorias de analise evocadas pelas áreas de concentração e pelas linhas de pesquisa dos programas e cursos de pós-graduação stritu senso no Brasil revelam e reforçam as bases principaís do conhecimento geográfico. Todavia a região, o territorio, o espaço e o ambiente além de realçarem a identidade do geográfico no âmbito do conhecimento cientifico moderno, evidenciam especificidades, riquezas e vanguardas da geografia brasileira. Quando se analisa este contexto e se constata esta realidade, soa estranho entender aquelas vozes que insistem em dizer que a geografia não tem um claro objeto de estudo, que não tem bases teoricas. Ou elas constituem uma aposta na negatividade da historia construida, ou revelam completo desconhecimento da geografia brasileira.

Comparados os dois grandes subramos do conhecimento geográfico moderno - excluindo aqui qualquer pensamento de caráter dicotomico - observa-se que na atualidade, e particularmente apos o apogeu do movimento da geografia critica brasileira, a geografia retoma muito de suas caracteristicas originais, algo que pode ser esquematizado como o mostra a figura 2. O esquema de fundo desta figura foi apresentado por Monteiro (1979) e representa os tres campos de interesse do conhecimento geográfico em três vertices de um triangulo, dois deles ligados à sociedade e um à "natureza"/ambientalismo. O esquema é revelador da natureza do pensamento geográfico enquanto atrelado ao campo das ciências humanas, ainda que acorde forte importancia à leitura e analise da dimensão "fisico-natural" do espaço geográfico (MENDONÇA, 1989).

Assim identificada sua evolução entre os anos 1960/1970, esta caracteristica da geografia brasileira parece prevalecer enquanto perspectiva geral na década seguinte, ou seja, percebe-se que, ainda que eivada de intensos debates e conflitos, ela se mantêm "à la fois" fisica e humana, com uma certa interação entre os dois subramos principaís.

Na década seguinte, com o enfraquecimento da predominante "renovação critica" da geografia, outros enfoques ganham destaque, e neste aspecto podem ser mencionadas a abordagem da geografia cultural, da social, das religiões, da representação, do turismo, da saude, etc. (Mendonça, F. e Kozel, 2003). A 
figura 4 apresenta um esquema representativo desta abertura do conhecimento geográfico na atualidade, testemunho de uma expressiva e rica plularidade. Ele torna-se mais complexo e, ao mesmo tempo, melhor definido quanto à sua identidade cientifica, pois que se observa tanto um importante recurso às bases teoricas e metodologicas da propria ciência quanto à proposição de abordagens novas na analise do espaço geografico.

Ao lado da corrente ambiental, cuja abordagem requer uma interação entre natureza e sociedade, estes subtemas ou especificades da geografia ganham importância e reforçam sua caracteristica de ciência humana. Esta perspectiva é ainda mais evidente no âmbito da pós-graduação stritu sensu, como esquematizado na figura 3, na qual se observa um predominio da abordagem social sobre a natural, o que é comprovado pelas categorias de analise geográfica evocadas nas áreas de concentração e linhas de pesquisa dos cursos.

\section{Processos de analise geografica na pós-graduação.}

Os processos de analise geográfica correspondem, no âmbito da presente abordagem, às instancias e estratégias utilizadas pelos geografos para o desenvolvimento da analise do espaço geográfico em sua constituição e evolução. Não sendo estático o espaço geográfico registra transformações permanentes decorrentes de eventos de ordem natural e/ou de atividades humanas. As alterações e mudanças que se manifestam devem ser então compreendidas, o que demanda o aporte de conhecimento de outros campos disciplinares, para que se possa construir a noção de dinâmica e evolução de uma determinada porção da superficie terrestre.

"Regionalização", "estruturação e re-estruturação", e "produção do espaço" aparecem como constantes de areas de concentração e ou linhas de pesquisas de dois cursos de pós-graduação em geografia no Brasil cada uma. Os dois ultimos processos fazem apelo tanto ao envolvimento de instâncias de poder quanto envolvem leituras relativas à vertente de renovação-critica marxista da geografia brasileira, enquanto o primeiro ressalta um enfoque mais amplo e clássico, pois que a regionalização têm sua origem no conhecido periodo clássico da geografia (ANDRADE, 1987).

A dinâmica do espaço aparece como constante de três áreas de concentração, sendo que sua menção não explicita muito claramente tendência para uma ou outra subdivisão do pensamento geográfico. Sob esta perspectiva tanto a sociedade quanto a natureza, em sua dimensão espacial, encontram possibilidades de analise, assim como temáticas mais especificas de estudo do interesse geográfico.

Planejamento, organização e ordenamento do espaço (e do territorio) são evocados em quatro (as duas primeiras) e cinco cursos / programas. Estes processos de dinâmica espacial revelam uma tendência marcante na geografia posterior aos anos cinquenta, momento no qual buscou-se ultrapassar a fase da descrição e produzir um conhecimento possivel de aplicação. Originariamente atrelados à politicas estatais e produzidos na perspectiva aplicada, os conhecimentos geográficos produzidos sob o enfoque destes processos privilegiaram ações intervencionistas de ação corretiva e propositiva; num segundo momento, porém, e sob influências do marxismo, passaram a enfocar a critica à ação do estado quando empregando o conhecimento para fins da manutenção e aprofundamento das disparidades e injustiças sociais.

Quadro 1: Categorias de analise geográfica conforme Áreas de 


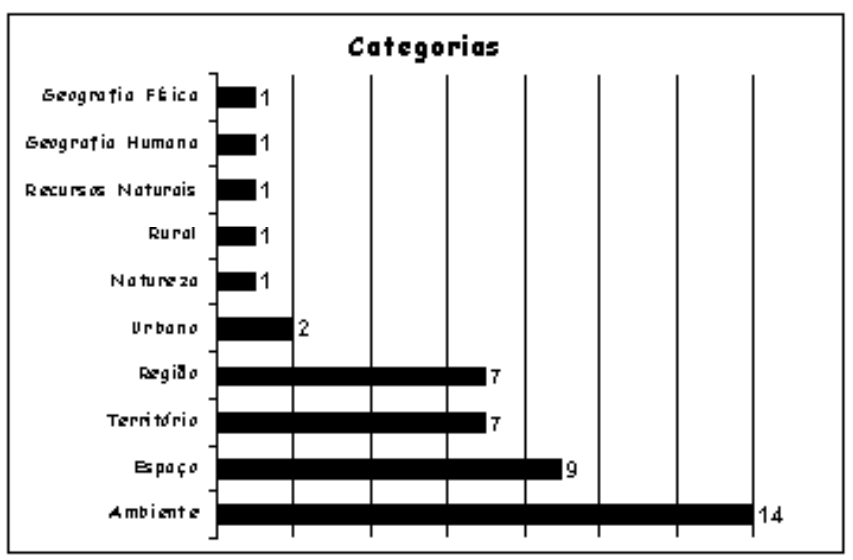

Fonte: www.capes.gov.br $(2005)$

Quadro 2: Processos enfocados na analise geográfica conforme as Áreas de

Concentração na Pós-Graduação em Geografia no Brasil

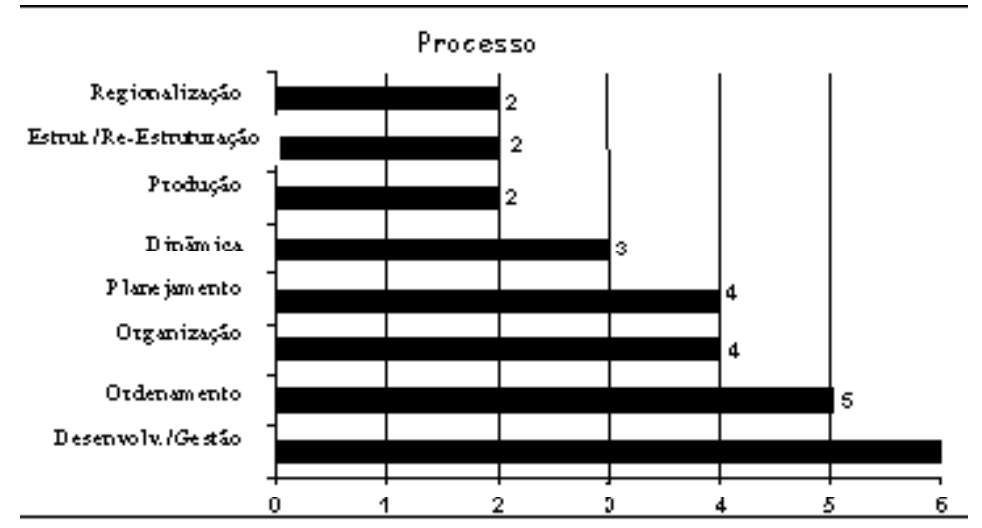

Fonte: www.capes.gov.br (2005)

A inserção dos três ultimos processos nos cursos e programas de pós-graduação revela ambas as têndencias mencionadas, ou seja, em alguns se observa maior interesse na formação de profissionais de alto nivel para analisar e propor intervenções na realidade (geografia aplicada), enquanto em outros o enfoque volta-se sobretudo à critica da aplicação de politicas publicas de planejamento e ordenamento do territorio. A identificação das duas tendências num mesmo curso, todavia, não causa espécie. 
Enfogues da Geografia na Atualidade

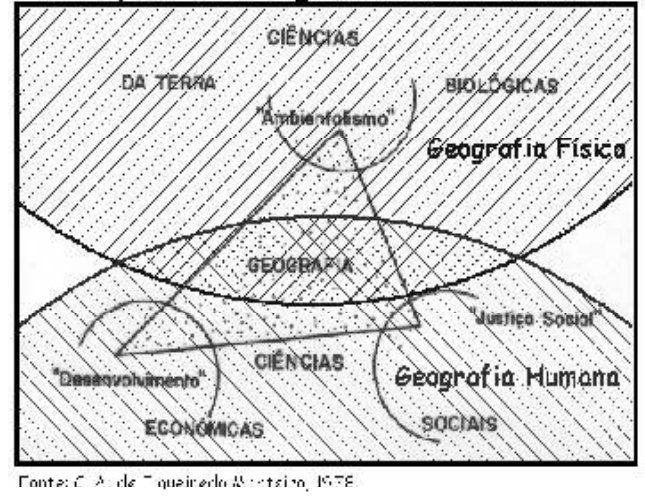

Figura 2: Enfoques da Geografia na Atualidade

Principal Enfoque da Geagrafia da Pós-Graduacăo no Brasil

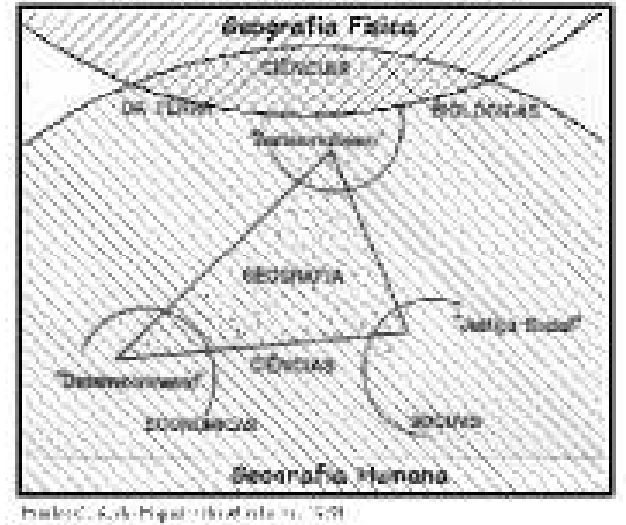

Figura 3: Principal Enfoque da Geografia da Pós-Graduação no Brasil

Obs.: As hachuras inclinadas, inseridas por este autor sobre o esquema de Monteiro (1979), atendem aos propósitos do presente texto. As hachuras inclinadas correspondem à classica macro-subdivisão da geografia, sendo que no sentido NE-SO correspondem ao campo da Geografia Física, e aquelas no sentido NO-SE ao campo da Geografia Humana. Adaptação feita por Mendonça, F.

Desenvolvimento e gestão aparecem como sendo os principaís processos buscados pelos cursos de pósgraduação para a analise da dinâmica do espaço geográfico, sendo evocados em seis deles. Atrelados a estes dois processos aparecem, praticamente, todas as categorias de analise, embora territorio e ambiente sejam evocados muito mais vezes que os demais e, ainda mais evidente, é a ligação entre gestão e ambiente. Os dois processos evidenciam a participação de atores sociais claramente definidos no processo de produção do espaço, sendo que o estado e a sociedade civil organizada ai ganham fundamental importância, tal é o caso da gestão dos recursos naturais, do meio ambiente, do espaço rural, urbano e regional. Neste particular o enfoque também contempla tanto a visão classica descritivo-analitica da geografia, quanto a 16 perspectiva intervencionista na busca do equacionamento de problemas socioespaciais e socioambientais. 


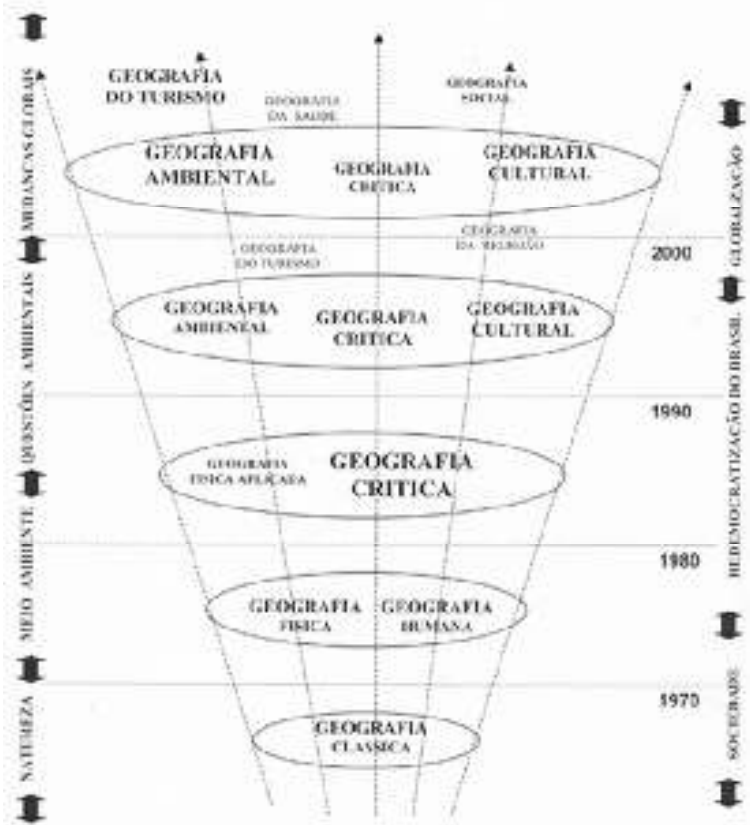

Figura 4: Evolução Recente da Geografia no Brasil a Partir das

Correntes ou Escolas de Pensamento Geografico (esquema simplificado)

Principaís

Assim analisados, os processos e as categorias revelam um estreito imbricamento, ou seja, às categorias mais evocadas associam-se processos de analise historicamente reconhecidos como pertinentes à elaboração do conhecimento geográfico. 'A esta realidade constituida pela pós-graduação em geografia no Brasil na atualidade vêm-se se juntar um importantissimo aporte da informática que, através principalmente do emprego do geoprocessamento (SIG - Sistema Geografico de Informações + Sensoriamento Remoto), têm rendido consideráveis avanços no ensino e na pesquisa deste campo do conhecimento no país. Muito mais do que ao aspecto institucional, os resultados positivos devem ser ainda reconhecidos aos grupos locais que, muitas vezes, constrõem a pós-graduação brasileira em condições de consideravel escassez econômica e dificuldade material.

\section{Lacunas, expectativas e desafios da formação em geografia na pós-graduação.}

A CAPES desenvolve uma ação altamente concentradora no que concerne à gestão da pós-graduação brasileira. Ela tem o monopolio da avaliação, recomendação e reconhecimento de todos os cursos de pós-graduação no país, além de gerenciar uma quantidade expressiva das verbas destinadas aos cursos e programas, diretamente ou via bolsas de estudo. Decorre desta concentração uma atitude quase policialesca e de ficalização do sistema, algo facilitado pelo centralismo na analise e decisão, mas que engessa a liberdade e a indepência da autogestão dos cursos e programas. Este fato parece refletir a propria sociedade brasileira, desacostumada que é de maior confiança nas instituições e transparência na gestão 
das atividades publicas. Vantagens e desvantagens podem ser facilmente identificadas no processo.

O sistema CAPES atua em mão dupla pois, ao mesmo tempo que permite abertura e liberdade na proposição temática para a criação de novos cursos, ou mudanças nos atuais, privilegia com editais especificos os setores de maior interesse do Governo. Ao mesmo tempo em que parece encorajar a proliferação de novos cursos, se vê limitada pela aplicação de modelos de avaliação fortemente alicerçados em principios norteadores das "ciências duras", isto para não falar no descompasso entre o crescimento do numero de cursos e programas e a dotação orçamentária para o funcionamento dos mesmos em boas condições.

No que concerne mais diretamente à Geografia, a atual distribuição-concentração geográfica tenderá a manter-se uma vez que os atuais critérios para aprovação e recomendação de novos cursos sejam mantidos. Por um bom tempo ainda o hinterland brasileiro terá que ser estudado nos bancos das escolas e laboratorios de cursos e programas localizados nos grandes centros, e a migração temporária dos interessados numa melhor qualificação ainda marcará a vida de inumeros geografos.

A Amazônia, para citar somente um exemplo, continuará a ser estudada sobretudo por instituições e pesquisadores estrangeiros, pois que a exigência da existência de uma massa critica e de uma considerável produção intelecutal local como requisito para a implementação de um programa de pós-graduação parece ainda não ter sido ali alcançada. A CAPES bem poderia encorajar a criação de uma proposta alternativa e apoiar sua implantação, em carater especial e regime de urgência, uma proposta que agregue o conhecimento ja adquirido e produzido por estudiosos brasileiros da Amazônia, autoctones e aloctones. Enquanto se aguarda o "estado otimo" das condições locais para a implantação de uma formação "ideal" e nos moldes de "exportação", se entrega o conhecimento da propria geografia da região à interessados externos de toda ordem. ó

Falta também à geografia o desenvolvimento de uma formação voltada ao estudo do Brasil, que o tome na escala da nação brasileira. Observa-se uma importante carência concernente à analise do territorio brasileiro, geopoliticamente definido, e de seu papel no processo de globalização atual. Nenhum curso ou programa em desenvolvimento no país apresenta, de maneira evidente e clara, areas de concentração especificamente concernentes à esta preocupação e à esta escala de abordagem. Ela parece, em primeira instância, revestir-se de extrema ousadia pois a dimensão espacial e as interações internacionais do Brasil são por deveras complexas. Mas, é preciso ousar... Num passado recente inumeros geografos produziram conhecimentos riquissimos sobre o contexto do país, e olhe que os os recursos tecnicos eram bem menos capazes!

Mas (mão na consciência!) uma pós-graduação, seja em que área for, somente logrará pleno sucesso, ou apresentará menos problemas, quando os niveis inferiores de ensino apresentarem resultados mais satisfatorios. Quando se observam os graves problemas sociais da população brasileira, dentre os quais destacam-se os baixos indices de alfabetismo e escolaridade básica, compreende-se que falta ainda muito para que a educação superior apresente melhorias. Não obstante, não se deve aguardar a melhoria de uma ponta da formação escolar-acadêmica para se investir na outra; a educação de um povo constitui um so processo, e é nele como um todo que se deve pensar.

Num tal contexto o sucesso obtido até o presente momento pela pós-graduação brasileira no geral, e pela geografia neste nivel em particular, é altamente louvável. As criticas aqui apresentadas conduzem a pensar numa pos-gradução que beira quase ao idealismo, à utopia. Mas, sonhar é preciso!

\section{Notas}

(1) Doutorado em Geografia / USP, Pos-doutorado Universtié de Sorbonne et London School of Tropical Medecine. 
Professor Titular do Departamento de Geografia da UFPR. Membro da Comissão de Avaliação da Area de Geografia da CAPES (1999-2002).

(2) Michel Maffesoli considera o Brasil o melhor exemplo de um "laboratorio da pos-modernidade", expressão que assinala a originalidade da vida economica, politica, cultural e social que marca o país e que lhe garante uma posição privilegiada no contexto da globalização e do futuro das nações... "uma mistura de informatica com candomblé". (Palestra proferida no encerramento do I Coloquio da APEB-Fr - Associação dos Estudantes e Pesquisadores Brasileiros na França. Paris, 29 de abril de 2005).

(3) A propria CAPES, através de seus representantes no I Coloquio da APEB-Fr, considera o modelo brasileiro de credenciamento e avaliação da pós-graduação muito concentrador, algo que não possui similar em outros países. Este mesmo sistema, que possui facilidade e agilidade de autofuncionamento e contrôle, apresenta também riscos evidentes de homogeneização de processos altamente diferenciados, o que exige que a comunidade mantenha-se permanentemene alerta e atuante na fiscalização das atividades do sistema.

(4) Evento realizado pelo Programa de Pós-graduação em Geografia da Univesidade Federal de Sergipe, intitulado Geografia 2001, no mês de setembro de 1998 na cidade de Aracaju em comemoração ao aniversario de 10 anos do programa. Um livro, organizado pelo programa e contendo as principaís contribuições, foi lançado no ano seguinte.

(5) Informação pessoal e oral do autor.

(6) Para Suertegaray (2003) as categorias espaço, região, territorio e paísagem constituem conceitos operacionais do conhecimento geografico.

\section{Referências}

ANPEGE - Associação Nacional de Pesquisa e Pós-graduação em Geografia. Revista da ANPEGE, n.1, 2003.

ANDRADE, Manuel Correia de. Geografia - Ciência da sociedade. Uma introdução à analise do pensamento geografico. São Paulo: Atlas, 1987.

HOBSBAWM, Eric. A era dos extremos. São Paulo: Atica, 1995.

IPEA - Instituto de Pesquisas Economicas. IDH-M - Indice de Desenvolvimento Humano Municipal do Brasil, 2004. www.ipea.gov.br

MATHEWS, John A. and DAVID, T. Herbert. Unifying geography - Common heritage, shared future. London: Routledge - Taylor \& Francis Group, 2004.

MENDONCA, Francisco. Geografia Fisica: Ciência Humana? São Paulo: Editora Contexto, 1989.

. Geografia ambiental. São Paulo: Editora Contexto, 1993.

. Dicotomia e dualidade da geografia moderna - A especificidade cientifica e o debate recente na geografia brasileira. Ra'e Ga - O espaço geografico em analise, V.1, 1999. Pp. 153-166.

Geografia socioambiental. In: Elementos de epistemologia da geografia contemporanea. Curitiba: Editora da UFPR, 2003. Pp. 121-144.

MENDONCA, Francisco e KOZEL, Salete. Elementos de epistemologia da geografia contemporanea. Curitiba: Editora da UFPR, 2003.

MONTEIRO, Carlos Augusto de Figueiredo. A geografia no Brasil (1934-1977): Avaliação e tendências. São Paulo: IGEO/USP, 1980.

A geografia no Brasil no século XX: Um panorama. Borrador, Revista AGB - São Paulo, 2001.

SERRES, Michel. Eclaircissements - Entretiens avec Bruno Latour. Paris; François Bourin, 1992. 
SILVA, Aldo Dantas da e GALENO, Alex (Orgs.). Geografia: Ciência do complexus. Porto Alegre: Sulina, 2005.

SUERTEGARAY, Dirce Maria Antunes. Geografia fisica (?) geografia ambiental (?) ou geografia e ambiente (?). in: Elementos de epistemologia da geografia contemporanea. Curitiba: Editora da UFPR, 2003. Pp. 111-120.

THERY, Hervé et MELLO, Nely Aparecida de. Atlas du Brésil. Paris: CNRS-Libergeo - La documentation française, 2004.

www.capes.gov.br $\underline{(2005)}$

Recebido em abril de 2005

Aceito em agosto de 2005 